\title{
Quench Embrittlement of Hardened 5160 Steel as a Function of Austenitizing Temperature
}

\author{
A. REGULY, T.R. STROHAECKER, G. KRAUSS, and D.K. MATLOCK
}

Charpy V-notch $(\mathrm{CVN})$ specimens from experimental heats of 5160 steel containing 0.001 and 0.034 mass pct phosphorus were austenitized at temperatures between $830{ }^{\circ} \mathrm{C}$ and $1100{ }^{\circ} \mathrm{C}$, quenched to martensite, and tempered at temperatures between $100{ }^{\circ} \mathrm{C}$ and $500{ }^{\circ} \mathrm{C}$. Scanning electron microscopy (SEM) was used to characterize the fracture surfaces of tested CVN specimens and carbide formation on prior austenite grain boundaries. Quench embrittlement, the susceptibility to intergranular fracture in as-quenched and low-temperature tempered high-carbon steels due to cementite formation as affected by phosphorus segregation on austenite grain boundaries, developed readily in specimens of the high phosphorus steel austenitized at all temperatures. The low phosphorus steel developed quench embrittlement only after austenitizing at $1100{ }^{\circ} \mathrm{C}$. Intergranular fractures correlated with low room-temperature CVN impact toughness. The results are discussed with respect to the dissolution of carbides during austenitizing and the effect of phosphorus on grain boundary, carbide formation, and stability.

\section{INTRODUCTION}

HARDENED carbon and low-alloy carbon steels are susceptible, depending on chemical composition and heat treatment, to intergranular fracture along prior austenite grain boundaries. Tempered martensite embrittlement and temper embrittlement are examples of well-studied, intergranular embrittlement phenomena. Both types of embrittlement are in part related to grain-boundary segregation of impurity elements and both develop during thermal processing after austenitizing and quenching to martensite. ${ }^{[1-4]}$ Tempered martensite embrittlement develops during tempering around $350{ }^{\circ} \mathrm{C}$ and temper embrittlement after tempering around $500{ }^{\circ} \mathrm{C}$. Hardness and strength decrease continuously with increasing tempering, and therefore, hardened steels that require high strengths and good toughness are generally tempered at temperatures below those that produce tempered martensite embrittlement.

Recently, however, a transition from ductile to intergranular fracture when steel carbon content exceeds 0.5 mass pct has been characterized in martensitic steels tempered at low temperatures. ${ }^{[5,6]}$ Under tensile or bending stress states, the higher carbon steels are highly susceptible to intergranular fracture in both the as-quenched condition and after tempering at low temperatures generally considered to be safe from embrittlement phenomena. In view of the fact that tempering is not required to render the microstructure susceptible to intergranular fracture, the latter embrittlement phenomenon is referred to as quench embrittlement. ${ }^{[7]}$

A. REGULY, Assistant Professor, and T.R. STROHAECKER, Professor, are with the Universidade Federal do Rio Grande do Sul (UFRGS), Porto Alegre, Brazil. G. KRAUSS, University Emeritus Professor, and D.K. MATLOCK, Armco Foundation Fogarty Professor, are with the Advanced Steel Processing and Products Research Center, Colorado School of Mines, Golden, CO 80401. Contact e-mail: dmatlock@mines.edu

Manuscript submitted October 7, 2002.
The role that phosphorus plays in various intergranular embrittlement phenomena in hardened carbon steels is well known. ${ }^{[1-4,8]}$ In tempered martensite embrittlement, cementite formation during tempering as a result of austenite transformation is also a critical factor. ${ }^{[2,9]}$ Phosphorus segregation and cementite formation are also related to quench embrittlement. ${ }^{[6,7]}$ However, instead of cementite formation during tempering, the cementite forms during austenitizing or quenching. As in the temper-driven embrittlement mechanisms, the grain-boundary structures are extremely fine and cannot be resolved by light microscopy. The presence of the cementite therefore is primarily documented by Auger electron spectroscopy of intergranular fracture surfaces. ${ }^{[10,11]}$ Phosphorus segregation exacerbates intergranular fracture and lowers the steel carbon content at which quench embrittlement occurs, especially in view of the fact that phosphorus segregation has been shown to occur during austenitizing. ${ }^{[1]}$ Figure 1 shows a composition map that defines regions of intergranular and transgranular fracture observed as a function $\mathrm{C}$ and $\mathrm{P}$ contents in low-temperature tempered martensite, ${ }^{[7]}$ and shows that the carbon content for intergranular fracture decreases with increasing phosphorus content. The effects of phosphorus are related to observations that phosphorus reduces the solubility of carbon in austenite, ${ }^{[12]}$ thus promoting cementite formation on austenite grain boundaries. ${ }^{[13]}$ The fact that quench embrittlement may develop even in steels without significant contents of phosphorus underscores the roles that carbon and grain-boundary carbide formation play in the phenomenon. These observations are consistent with other work that shows intergranular fracture in tempered steels with extremely low phosphorus contents. $^{[14]}$

The purpose of this article is to present the results of an investigation performed to determine the effects that systematic increases in austenitizing temperature have on quench embrittlement. Temperature-dependent grain size and grain-boundary structure effects were examined. Experimental steels with high and low phosphorus content and with compositions equivalent to SAE 5160, 
a widely used commercial steel, were selected for study. The nominal 0.6 mass pct carbon content of the 5160 steel places it close to the borderline (Figure 1) of the transition between ductile transgranular and brittle intergranular fracture in as-quenched and low-temperature tempered conditions.

\section{EXPERIMENTAL}

Two steels, one containing 0.034 mass pct $\mathrm{P}$, and designated the high-P steel, and the other containing 0.001 mass pct $\mathrm{P}$, and designated the low-P steel, were vacuummelted to SAE 5160 chemistry (Table I). The ingots were forged at $1200{ }^{\circ} \mathrm{C}$, subsequently rolled at $1200{ }^{\circ} \mathrm{C}$ to $16-\mathrm{mm}$-thick plate, and slowly cooled in vermiculite. Charpy V-notch (CVN) specimens were machined and austenitized at temperatures between $830^{\circ} \mathrm{C}$ and $1100{ }^{\circ} \mathrm{C}$, in either salt baths or stainless steel bags to prevent decarburization, and quenched in oil. Specimens austenitized at $830{ }^{\circ} \mathrm{C}$ and $920{ }^{\circ} \mathrm{C}$ were held for 30 minutes and specimens austenitized at $1000{ }^{\circ} \mathrm{C}$ and $1100{ }^{\circ} \mathrm{C}$ were held for 1 hour. Specimens were tempered at $100^{\circ} \mathrm{C}, 150{ }^{\circ} \mathrm{C}$, $200{ }^{\circ} \mathrm{C}, 300{ }^{\circ} \mathrm{C}, 400{ }^{\circ} \mathrm{C}$, or $500{ }^{\circ} \mathrm{C}$ in oil or salt baths for 1 hour.

Metallographically prepared surfaces were etched with 2 pct nital to show matrix microstructural features, and with a solution of $450 \mathrm{~mL}$ distilled water, $15 \mathrm{~g}$ picric acid, and $80 \mathrm{~g}$ dodecylbenzene sulfonate to show prior-austenite grain boundaries. The CVN specimens were broken at room temperature and the fracture surfaces examined by scanning electron microscopy (SEM). Qualitative identification of carbides on fracture surfaces were made by

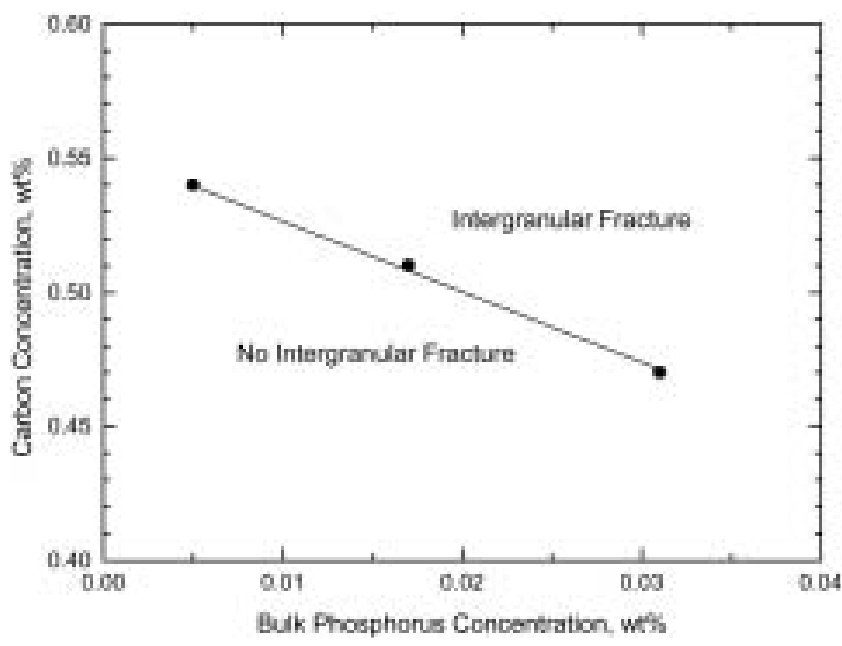

Fig. 1-Carbon concentration as a function of bulk phosphorus concentration showing delineation between intergranular and transgranular fracture mode. ${ }^{[7]}$ energy dispersive spectroscopy (EDS) with a beryllium window. Other experimental details are summarized elsewhere. ${ }^{[15]}$

\section{RESULTS}

\section{A. Microstructure and Hardness}

All specimens showed uniform martensitic or tempered martensitic microstructures. ${ }^{[15]}$ The martensite was typical of lath martensite that forms in medium-carbon steels, ${ }^{[16]}$ with the laths in packets aligned parallel to one another. The sizes of most of the features of the matrix structure, including most of the martensite laths, carbides retained during austenitizing, interlath retained austenite, and carbides produced during tempering, were too fine for resolution in the light microscope. Other work, by Mössbauer emission spectroscopy (MES), has shown that the retained austenite content of hardened 5160 steel in the as-quenched condition is about 9 pct, and that that amount of retained austenite remains stable after tempering at temperatures up to $200{ }^{\circ} \mathrm{C} .{ }^{[17]}$ Tempering at higher temperatures causes the retained austenite to transform to interlath mixtures of ferrite and carbide. The coarse interlath cementite crystals that form from transformation of the retained austenite are responsible for one of the forms of tempered martensite embrittlement. ${ }^{[18]}$

Carbides that are spheroidized and retained after austenitizing, on the order of $50 \mathrm{~nm}$ in size for standard commercial austenitizing treatments of medium-carbon steels at temperatures around $850^{\circ} \mathrm{C}$, are important sites of microvoid initiation during ductile, transgranular fracture of mediumcarbon martensitic steels. ${ }^{[6]}$ As austenitizing temperatures increase, carbides dissolve, and more carbon and carbideforming elements such as $\mathrm{Cr}$ go into solution in the austenite. Figure 2 shows SEM micrographs, taken from deeply etched metallographic specimens, of the microstructure of the high-P 5160 steel austenitized at $830{ }^{\circ} \mathrm{C}$ and $1100{ }^{\circ} \mathrm{C}$, in the as-quenched condition and tempered at $500{ }^{\circ} \mathrm{C}$. High densities of relatively coarse undissolved carbides, many on the order of $2 \mu \mathrm{m}$ in size, are present in the specimens austenitized at $830^{\circ} \mathrm{C}$ (Figures 2(a) and (b)), and almost no carbides are retained after austenitizing at $1100{ }^{\circ} \mathrm{C}$ (Figures 2(c) and (d)). Fine carbides are produced by tempering of the martensitic microstructures at $500{ }^{\circ} \mathrm{C}$ (Figures 2(b) and (d)).

Figure 3 shows prior austenite grain size as a function of austenitizing temperature for the high-P and low-P 5160 steels. Consistent with the fact that the steels were Al-killed, austenite grain size changes little for austenitizing temperatures up to $1000{ }^{\circ} \mathrm{C}$. However, at temperatures at which AlN particles dissolve, significant austenite grain growth occurred. The grain coarsening is much less in the high-P steel, a result that may be attributed to the somewhat higher

Table I. Elemental Compositions of 5160 Experimental Steels (in Weight Percent)

\begin{tabular}{lccccccccccccc}
\hline Alloy & $\mathrm{C}$ & $\mathrm{Mn}$ & $\mathrm{P}$ & $\mathrm{Si}$ & $\mathrm{Cr}$ & $\mathrm{Ni}$ & $\mathrm{Sn}$ & $\mathrm{Al}$ & $\mathrm{S}$ & $\mathrm{Mo}$ & $\mathrm{Cu}$ & $\mathrm{O}(\mathrm{ppm})$ & $\mathrm{N}(\mathrm{ppm})$ \\
\hline High-P & 0.63 & 0.83 & 0.034 & 0.26 & 0.79 & 0.12 & 0.001 & 0.037 & 0.001 & 0.04 & 0.01 & 25 & 66 \\
Low-P & 0.61 & 0.85 & 0.001 & 0.25 & 0.80 & 0.13 & 0.001 & 0.027 & 0.001 & 0.04 & 0.01 & 27 & 62 \\
\hline
\end{tabular}



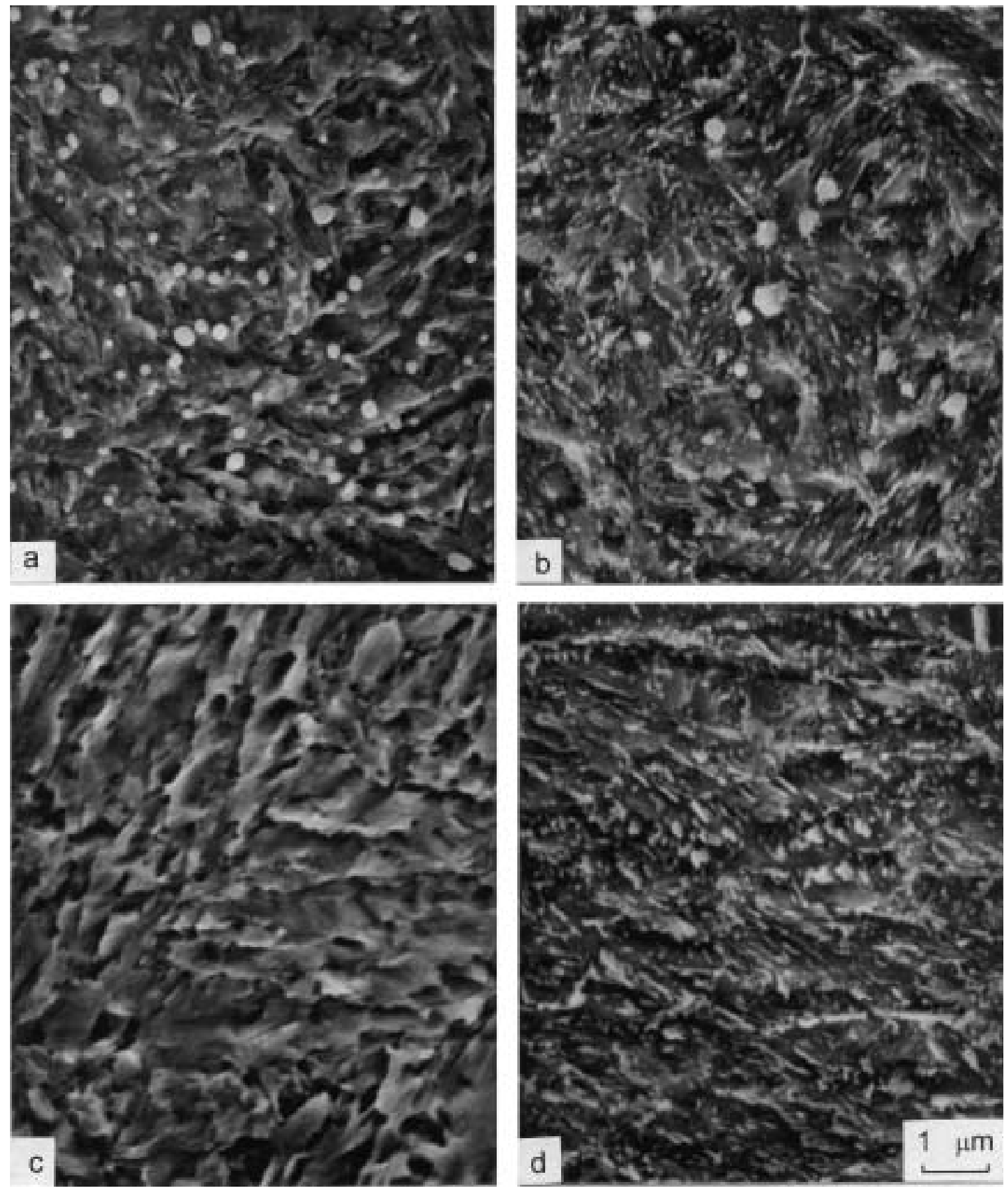

Fig. 2-Matrix carbide morphology in SAE 5160 high-P steel austenitized $(a)$ and $(b)$ at $830{ }^{\circ} \mathrm{C}$ and $(c)$ and $(d)$ at $1100{ }^{\circ} \mathrm{C} .(a)$ and $(c)$ As-quenched conditions and $(b)$ and $(d)$ after a $1 \mathrm{~h} 500{ }^{\circ} \mathrm{C}$ temper.

Al content ( 0.037 vs 0.027 mass pct) of the high-P steel. Phosphorus also retards spheroidization and dissolution of cementite during tempering and low-temperature austenitizing. ${ }^{[19,20]}$ However, the retention of carbide particles due to phosphorus and their restraint on austenite grain growth is unlikely, especially in view of the absence of observable particles in specimen austenitized at $1100{ }^{\circ} \mathrm{C}$, as shown in Figure 2(c).

Figure 4 shows hardness as a function of tempering temperature for the high- and low-P 5160 steels austenitized at the various temperatures. The hardness of the steels, austenitized at the lowest temperature of $830{ }^{\circ} \mathrm{C}$, remains consistently higher at all tempering temperatures than the hardness of specimen austenitized at higher temperatures. This observation may be a result of the increased austenitic grain size of specimen austenitized at higher temperatures, an effect that has been shown to reduce strength in hardened steels. ${ }^{[21]}$ The lower hardness of the specimen austenitized at $920{ }^{\circ} \mathrm{C}$ and above may also be in part a result of the increased solution of carbon, and the carbide-forming 


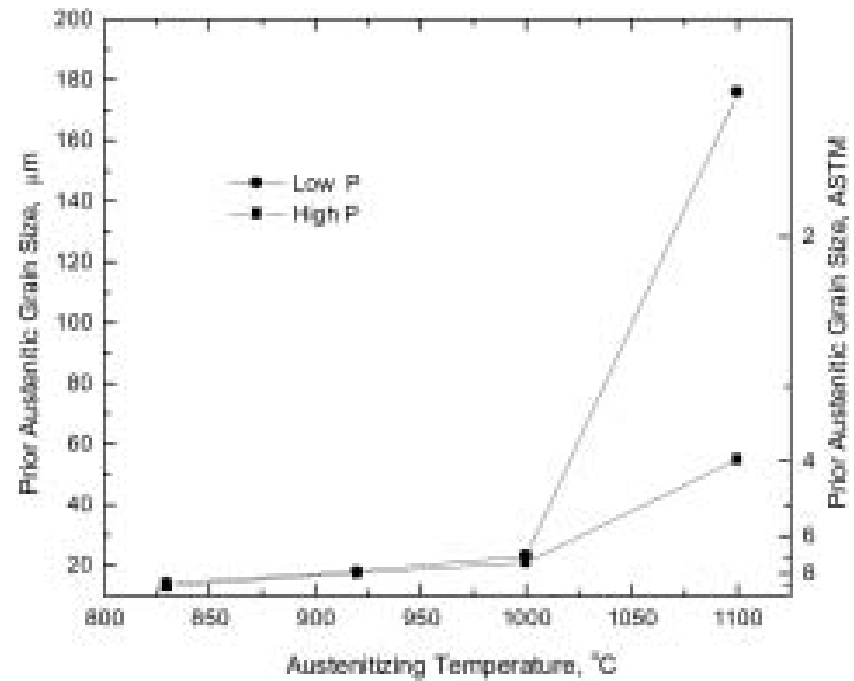

Fig. 3-Prior austenite grain size as a function of austenitizing temperature for both low- and high-P steels.

elements manganese and chromium, with increasing austenitizing temperatures. The increased solution of these elements would increase retained austenite, lowering hardness after tempering at temperatures where the austenite was stable, and lowering hardness due to the coarser distributions of carbides formed by the transformation of the retained austenite after tempering at higher temperatures.

\section{B. CVN Impact Toughness and Fracture Surface Characterization}

The results of the CVN testing as a function of austenitizing and tempering are shown in Figure 5. Impact toughness is very low in the as-quenched condition for both steels, but somewhat higher in the low-P steel. With increasing tempering, the curves for the low- and high-P steels diverge. The low-P steel has consistently higher toughness than does the high-P steel and shows the characteristic plateau in roomtemperature toughness associated with tempered martensite embrittlement. ${ }^{[1-3,9]}$ In contrast, the very low as-quenched toughness of the high-P hardened steel persists almost unchanged, independent of austenitizing temperature, until tempering temperatures reach $400{ }^{\circ} \mathrm{C}$, despite major decreases in hardness. Even after tempering at $400{ }^{\circ} \mathrm{C}$ and $500{ }^{\circ} \mathrm{C}$, the impact toughness of the high-P steel remains very low compared to that of the low-P steel tempered at the same temperatures.

Figures 6 through 9 show fracture surfaces from the lowand high-P 5160 steels. All of the SEM micrographs were taken at the same location: in the center of a CVN fracture surface at a distance of about $0.5 \mathrm{~mm}$ from the root of the machined notch. Each figure shows, for a given tempering condition, the fracture surfaces associated with both steels austenitized at $830{ }^{\circ} \mathrm{C}, 920^{\circ} \mathrm{C}, 1000^{\circ} \mathrm{C}$, and $1100{ }^{\circ} \mathrm{C}$.

The as-quenched series (Figure 6) establishes that quench embrittlement occurs without tempering for the high-P steel after austenitizing at all temperatures and for the low-P steel austenitized at high temperatures. The low-P steel, austenitized at temperatures typically used in commercial practice,

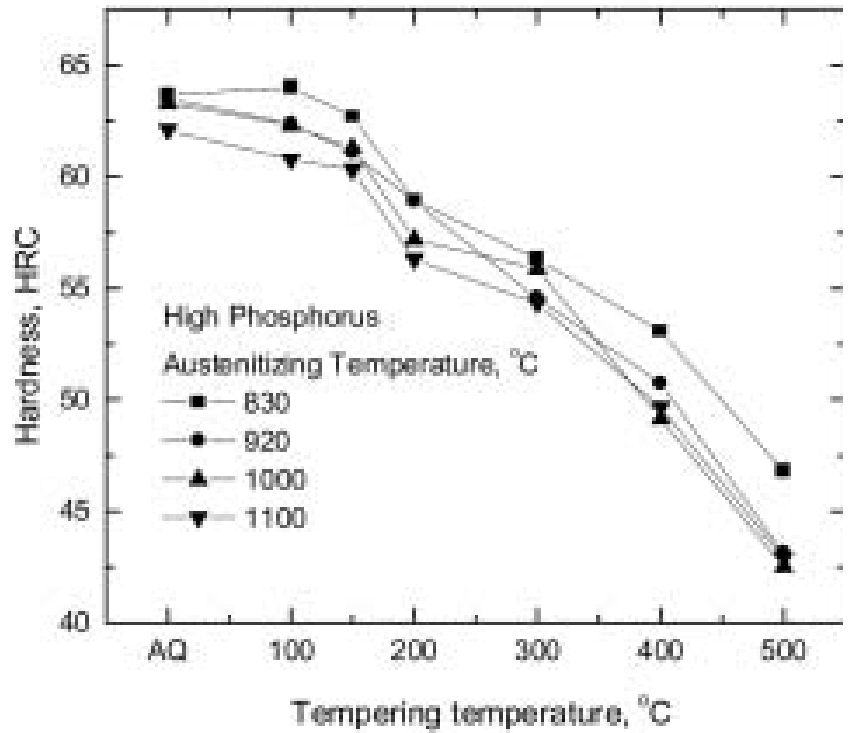

(a)

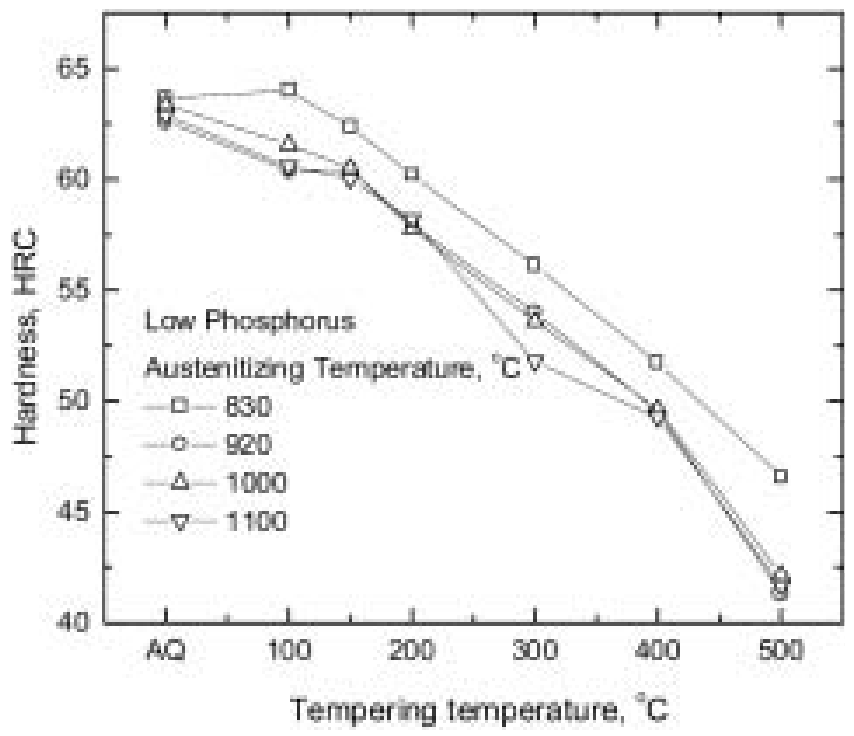

(b)

Fig. 4-Hardness $v s$ tempering temperature for the experimental low- and high-P SAE 5160 steel austenitized from $830{ }^{\circ} \mathrm{C}$ to $1100{ }^{\circ} \mathrm{C}$, oil quenched, and tempered $1 \mathrm{~h}$ at temperatures shown: $(a)$ high-P material and $(b)$ low$\mathrm{P}$ material.

fractures by transgranular mechanisms. The impact toughness is low despite the fact that the as-quenched fracture surface is composed of microvoids typical of ductile fracture in hardened medium- and high-carbon steels consisting of microstructures of dispersed carbides in a matrix of highcarbon martensite. ${ }^{[22]}$ The closely spaced carbides provide a high density of closely spaced sites for microvoid coalescence and the high-carbon martensitic matrix has a very high rate of strain hardening that limits plasticity. ${ }^{[5,6]}$ Thus, under lowaustenitizing-temperature conditions, the low $\mathrm{P}$ steel is not subject to quench embrittlement, despite its high carbon content. The intergranular fracture surfaces (Figures 6(d) and (h)) also demonstrate the austenite grain size differences developed between the two steels after austenitizing at $1100{ }^{\circ} \mathrm{C}$, as 
noted in Figure 2. However, the finer austenitic grain size of the high-P steel is not sufficient to offset the detrimental effects of grain-boundary cementite formation and phosphorus segregation on fracture.

In contrast to the as-quenched samples, tempering at $200{ }^{\circ} \mathrm{C}$ produces little change in the fracture surfaces of the

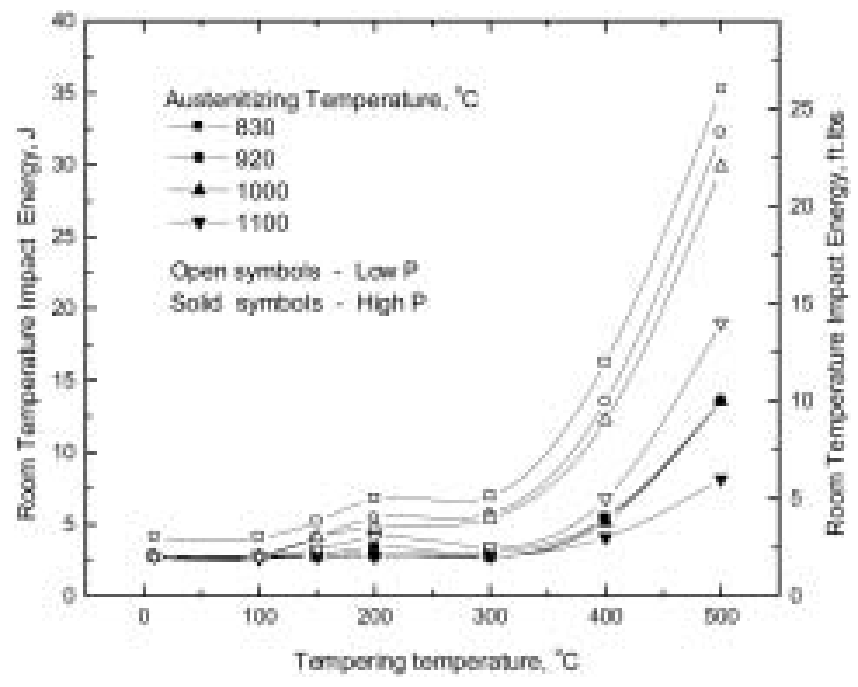

Fig. 5-Room-temperature $\mathrm{CvN}$ impact energy vs tempering temperature for the experimental SAE 5160 steels austenitized from $830^{\circ} \mathrm{C}$ to $1100^{\circ} \mathrm{C}$, oil quenched, and tempered $1 \mathrm{~h}$ at temperatures shown. various specimens, as shown in Figure 7. However, as shown in Figure 8, after tempering at $300{ }^{\circ} \mathrm{C}$, significant amounts of intergranular fracture appear on the fracture surfaces of the low-P steel even after low-temperature austenitizing. The $300{ }^{\circ} \mathrm{C}$ tempering treatment is in the middle of the temperature range for tempered martensite embrittlement, and therefore, the increased intergranular fracture correlates well with the tempered-martensite-embrittlement plateau shown in Figure 5 for the low-P steel.

Tempering at $500{ }^{\circ} \mathrm{C}$ produces transgranular fracture in all of the low-P specimens, as shown in Figure 8. The low-P specimen austenitized at $1100{ }^{\circ} \mathrm{C}$ (Figure 9(d)) also shows largely transgranular fracture. The residual intergranular fracture correlates with the lower impact toughness of the $1100{ }^{\circ} \mathrm{C}$-austenitized specimen, compared to the toughness of the specimens austenitized at lower temperatures, as shown in Figure 5. The fracture surfaces of the high-P steel specimens tempered at $500{ }^{\circ} \mathrm{C}$ (Figures 9(e) to (h)) show small amounts of transgranular fracture, but still largely consist of brittle intergranular facets on prior austenite grain boundaries, particularly after austenitizing at high temperatures.

\section{Cementite Formation on Austenite Grain Boundaries}

Evidence for cementite formation on austenite grain boundaries of quench-embrittled CVN specimens is presented in Figures 10 through 12. Figure 10(a) shows
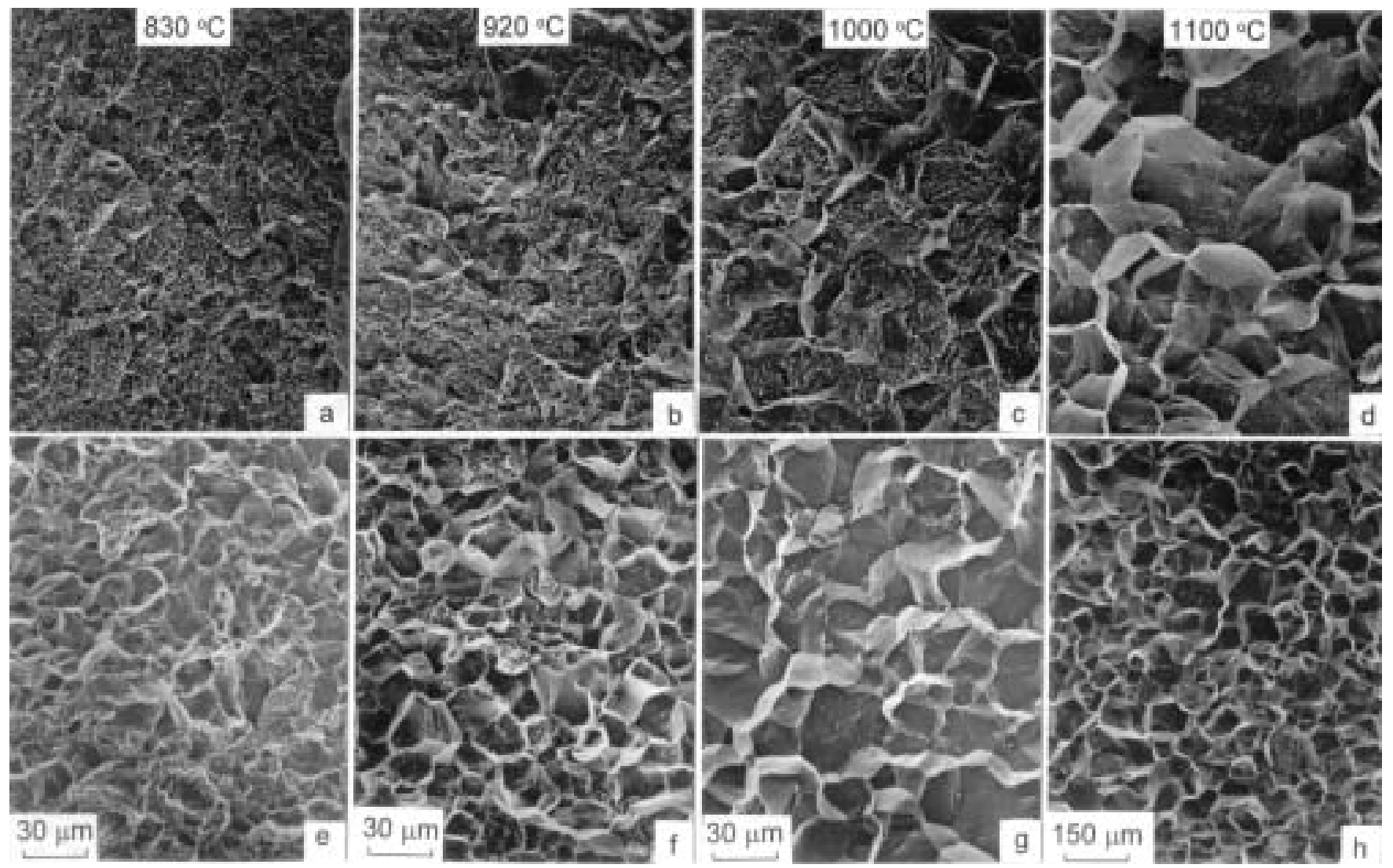

Fig. 6-Fracture surfaces of SAE 5160 martensitic $(a)$ through $(d)$ low-P steel and $(e)$ through $(h)$ high-P steel as quenched from the following austenitizing temperatures: $(a)$ and $(e) 830^{\circ} \mathrm{C} ;(b)$ and $(f) 920^{\circ} \mathrm{C} ;(c)$ and $(g) 1000^{\circ} \mathrm{C}$; and $(d)$ and $(h) 1100{ }^{\circ} \mathrm{C}$. Note $(d)$ and $(h)$ at a lower magnification. SEM micrographs. 

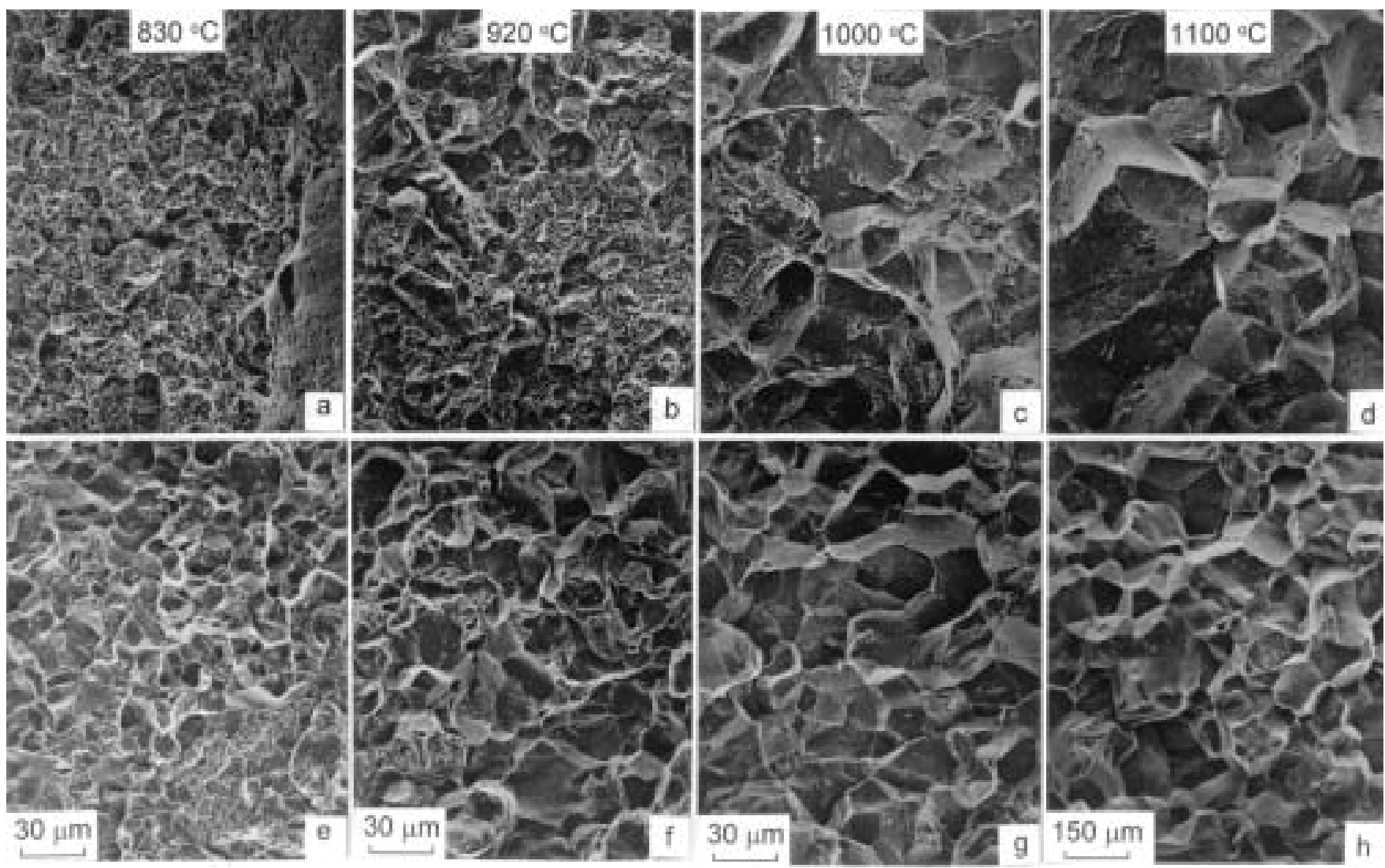

particles on a grain-boundary fracture surface of as quenched low-P steel austenitized at $1100{ }^{\circ} \mathrm{C}$. The EDS spectra (Figure 10(b)) show qualitatively the high C content of the particles and low $\mathrm{C}$ content of the surrounding flat areas of the boundary, providing evidence that the particles are carbides. Arrays of carbide particles that grow from austenite grain boundaries in both high- and low-P as-quenched specimens are shown in Figure 11. The parallel arrays represent incipient nucleation and growth of cementite grain boundary allotriomorphs. ${ }^{[23]}$ Such particles have been shown to eventually combine to form networks of continuous grain-boundary cementite particles with stepped, ledge interfaces when the nucleating, parallel crystals grow together. ${ }^{[24]}$ Other examples of the early stages of continuous cementite allotriomorph formation by sets of parallel cementite crystals are shown in Figure 12. Although Figures 10 through 12 show examples of carbides that have formed on prior austenite grain boundaries, there are still significant grain-boundary areas that appear to be free of resolvable carbide particles. Reasons for this observation are presented in the discussion.

\section{DISCUSSION}

The results presented in the above sections establish a number of characteristics of quench embrittlement in hardened low-alloy steels. Austenitizing conditions and phosphorus content contribute to the development and persistence of critical levels of grain-boundary cementite formation for intergranular fracture, with the highest austenitizing temperatures and highest phosphorus contents providing the highest susceptibility to quench embrittlement. The higher austenitizing temperatures result in greater solution of carbides, as demonstrated by the micrographs shown in Figure 2, and as a result provide more carbon for cementite formation at austenite grain boundaries during high-temperature austenitizing and quenching. Thus, even the low-P steel specimens, without the stimulating effect of $\mathrm{P}$ on cementite growth and stability, developed critical concentrations of carbides as a result of austenitizing at $1100{ }^{\circ} \mathrm{C}$, leading to the intergranular fracture observed in Figure 6(d).

At lower austenitizing temperatures, retained carbides lower the carbon content of the austenite, below 0.6 pct $C$, and thus to a value below the critical level necessary for grain-boundary fracture. Therefore, although the 0.6 mass pct carbon in the low-P 5160 steel is expected to cause intergranular fracture according to the map shown in Figure 1, quench embrittlement did not develop because the carbides retained during austenitizing at $830{ }^{\circ} \mathrm{C}$ effectively lowered the austenite carbon content. As a result, as shown in Figure 6, transgranular fracture, rather than intergranular fracture, of as-quenched specimens occurred on impact loading. The use of intercritical austenitizing treatments in the austenite-carbide two-phase field in high-carbon steels, such as 52100, is well known to reduce austenite carbon contents to levels that promote transgranular 

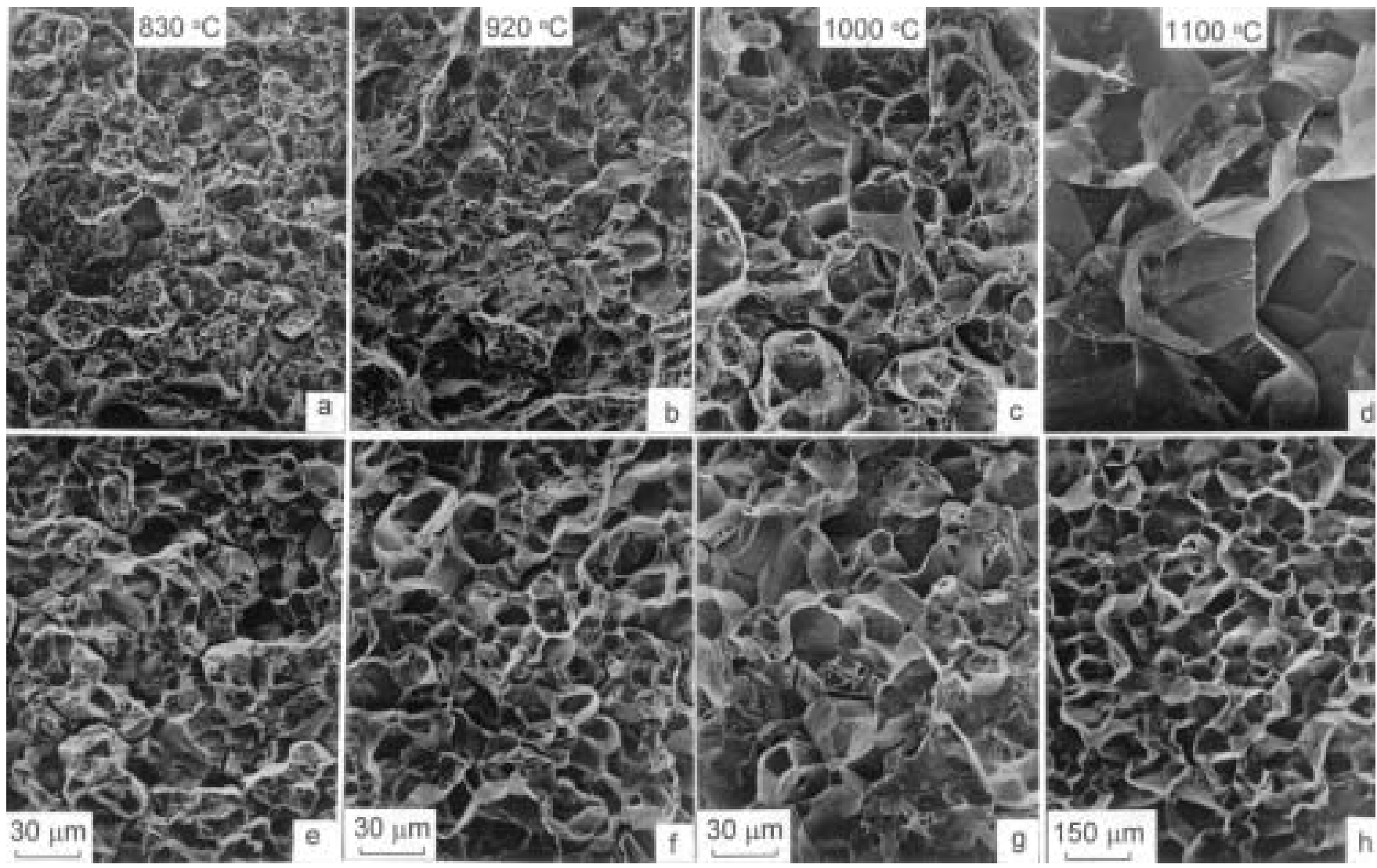

Fig. 8-Fracture surfaces of SAE 5160 martensitic $(a)$ through $(d)$ low-P steel and $(e)$ through $(h)$ high-P steel tempered at $300{ }^{\circ} \mathrm{C}$. Prior to quenching, the samples were austenitized at the following temperatures: $(a)$ and $(e) 830{ }^{\circ} \mathrm{C} ;(b)$ and $(f) 920{ }^{\circ} \mathrm{C} ;(c)$ and $(g) 1000{ }^{\circ} \mathrm{C}$; and $(d)$ and $(h) 1100{ }^{\circ} \mathrm{C}$. Note $(d)$ and (h) at a lower magnification. SEM micrographs.

rather than intergranular fracture in hardened steels tempered at low temperatures. ${ }^{[5,6]}$

In contrast to the low-P steel, the high phosphorus content of the high-P steel is sufficient to stimulate critical grainboundary cementite coverage for intergranular fracture even with significant amounts of carbides retained, and the associated reduction of matrix carbon content, after austenitizing at $830{ }^{\circ} \mathrm{C}$. This result is consistent with the fracture map shown in Figure 1. For example, in steel containing 0.034 mass pct phosphorus, intergranular fracture would be expected with matrix carbon contents as low as $0.46 \mathrm{pct}$ carbon.

The intergranular fracture associated with quench embrittlement significantly lowers room temperature impact toughness, as shown in Figure 5. Increased tempering rapidly increases impact toughness in the low-P steel specimens that did not develop quench embrittlement. In the low-P steel that developed quench embrittlement after austenitizing at $1100{ }^{\circ} \mathrm{C}$, the improvement of impact toughness with increasing temperature was less than that observed in specimen austenitized at lower temperatures. Intergranular fracture was replaced by microvoid formation around spheroidized grain-boundary carbides, as shown in Figure 9. Recovery of impact toughness is reduced in the high-P steel, Figure 5, a result that can be attributed to the strong effect of phosphorus in retarding cementite particle growth and spheroidization as observed by James in 5160 steel with high phosphorus contents. ${ }^{[19]}$
Despite the observation of cementite crystals on prior austenite grain boundaries, many areas of quench-embrittled grain boundaries are carbide free and quite smooth. Apart from possible phosphorus segregation, it is also possible that other elements, in particular $\mathrm{Mn}$ and $\mathrm{Si}$, segregate in very thin films to the austenite grain boundaries. The literature documents a number of studies that have shown that $\mathrm{Mn}$ and $\mathrm{Si}$ contribute to intergranular fracture in tempered steels. ${ }^{[25-28]}$ Recently, high Mn content has been shown to directly cause quench embrittlement in steels based on SAE 5140 steel. ${ }^{[29]}$ In the latter study, two heats, identical in composition except for Mn content, 0.82 vs 1.83 , were subjected to tensile testing in the asquenched condition. The steel containing $0.82 \mathrm{Mn}$ failed by ductile, transgranular microvoid coalescence, while the steel containing $1.83 \mathrm{Mn}$ failed by brittle intergranular fracture.

\section{CONCLUSIONS}

The following conclusions are based on a study of the effect of austenitizing temperature, tempering temperature, and phosphorus content on the susceptibility of hardened 5160 steel to quench embrittlement. According to earlier work, the 0.6 mass pct carbon content of 5160 steel places the steel in the carbon range for steels highly susceptible to the intergranular fracture characteristic of quench 

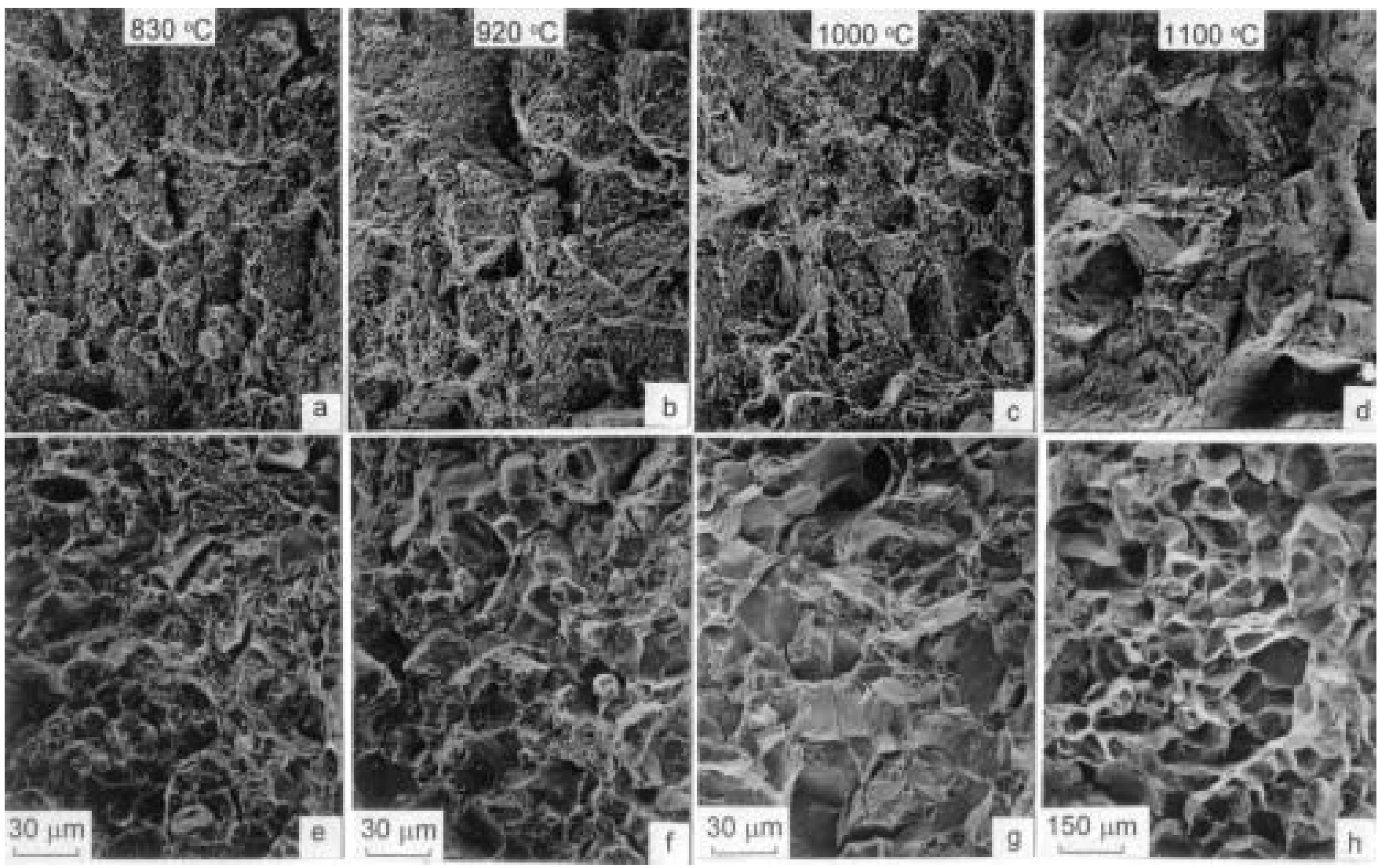

Fig. 9-Fracture surfaces of SAE 5160 martensitic $(a)$ through $(d)$ low-P steel and $(e)$ through $(h)$ high-P steel tempered at $500{ }^{\circ} \mathrm{C}$. Prior to quenching the samples were austenitized at the following temperatures: $(a)$ and $(e) 830{ }^{\circ} \mathrm{C} ;(b)$ and $(f) 920{ }^{\circ} \mathrm{C} ;(c)$ and $(g) 1000{ }^{\circ} \mathrm{C}$; and $(d)$ and $(h) 1100{ }^{\circ} \mathrm{C}$. Note $(d)$ and (h) at a lower magnification. SEM micrographs.

embrittlement in as-quenched and low-temperature tempered conditions.

1. Quench embrittlement is associated with intergranular fracture along prior austenite grain boundaries embrittled by phosphorus and cementite formation. Other elements, such as Mn, may also contribute to the intergranular fracture.

2. High austenitizing temperatures increase carbide dissolution in austenite, and thereby increase the carbon available for cementite formation at austenite grain boundaries during austenitizing and quenching.

3. Quench embrittlement is suppressed in 5160 steels austenitized between $830{ }^{\circ} \mathrm{C}$ and $920^{\circ} \mathrm{C}$, a temperature range typically used commercially for austenitizing 5160 steel, provided phosphorus content is reduced to very low levels. This result is attributed to the low level of phosphorus and the retention of spheroidized carbides that lower the carbon content of austenite to below the critical level for intergranular embrittlement.

4. Quench embrittlement readily develops in 5160 steels with high residual levels of phosphorus, even after austenitizing at low temperatures where high densities of spheroidized carbide particles are retained.

5. High austenitizing temperatures, at which retained carbides are largely dissolved, increase susceptibility to quench embrittlement, even in low phosphorus-containing steels. Coarse austenite grain-boundary structures formed at high temperatures would also lead to concentrations in P segregation.

6. Room-temperature impact toughness of quench and tempered specimens is severely reduced by the residual intergranular fracture associated with quench embrittlement. The recovery of good impact toughness by high-temperature tempering is retarded in hardened 5160 steel with high phosphorus content.

\section{ACKNOWLEDGMENTS}

This article is based on the Ph.D. thesis of A. Reguly conducted under a joint education and research program between the Colorado School of Mines (Golden, CO) and the Universidade Federal do Rio Grande do Sul (Porto Alegre, Brazil). The experimental steels were provided by The Timken Company, courtesy of John Murza, and the machining of the CVN specimens was performed by Caterpillar, Inc., courtesy of Dennis O'Neil. Research support for one of the authors (AR) was provided by the Fulbright Commission and Conselho de Aperfeicoamento de Pessoal de Nivel Superior-Brazil (CAPES), and the Advanced Steel Processing and Products Research (ASPPRC), a cooperative university/industry research center at the Colorado School of Mines, provided other funds for the research. 


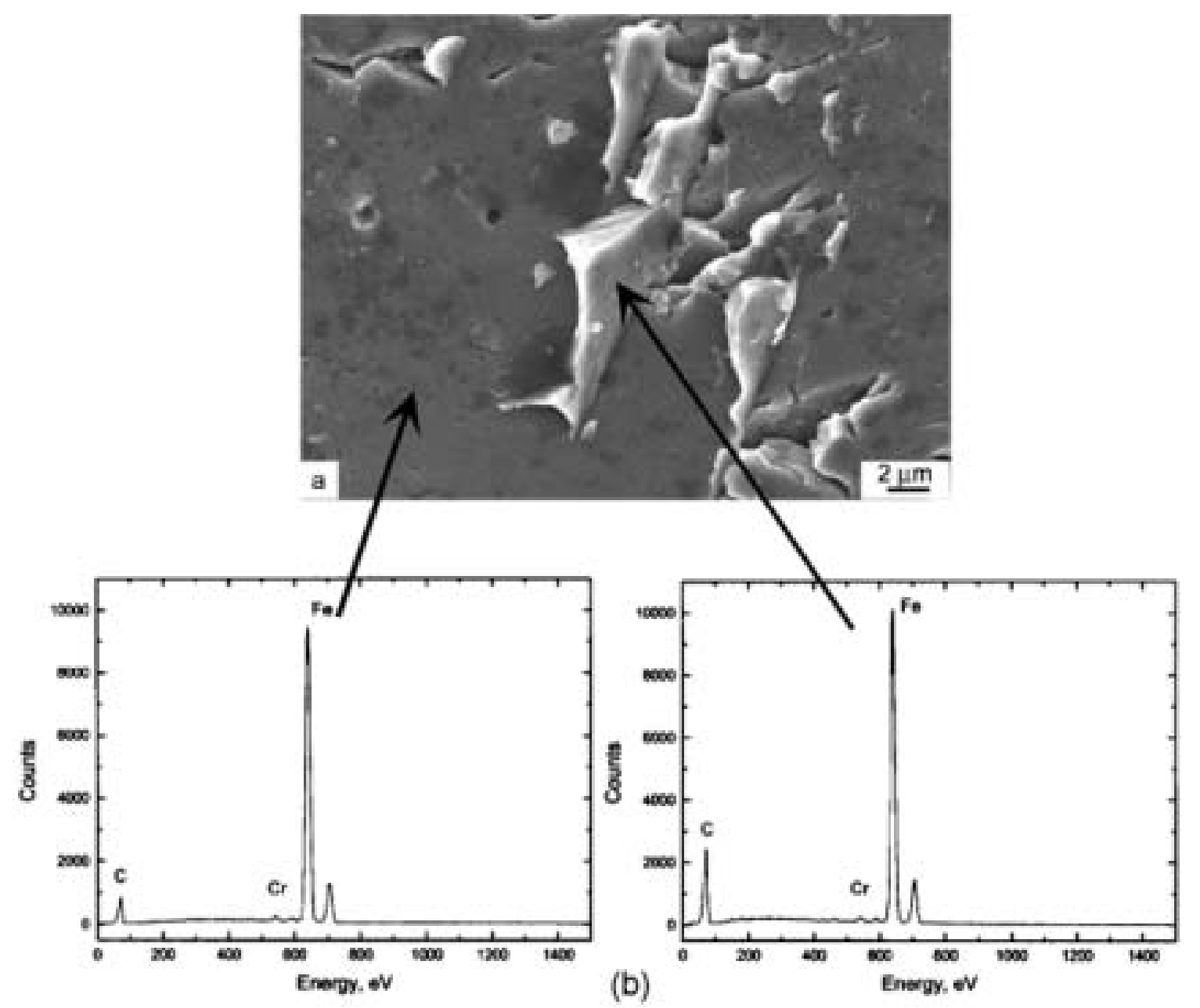

Fig. 10-(a) Intergranular fracture surface of as-quenched low-P SAE 5160 steel austenitized at $1100{ }^{\circ} \mathrm{C}$ and $(b)$ the corresponding EDS spectra obtained from regions indicated by arrows.
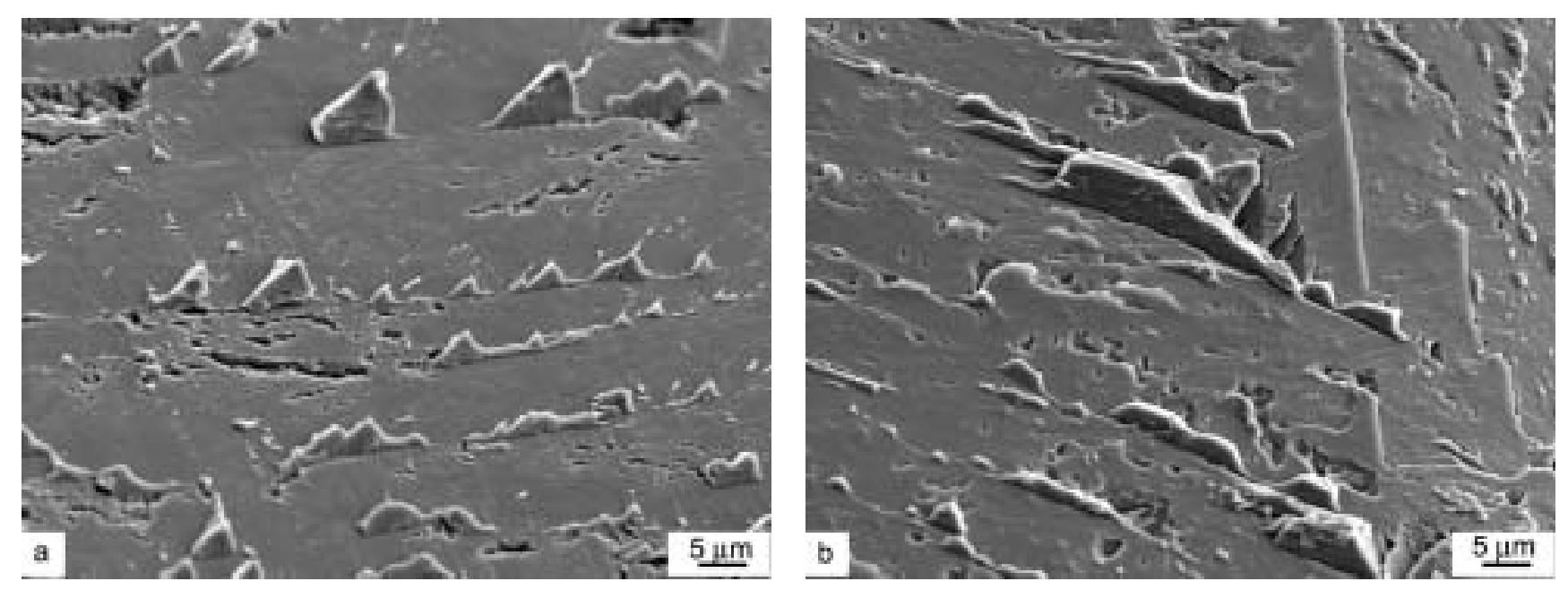

Fig. 11-Regions of intergranular fracture on as-quenched SAE 5160 steel austenitized at $1100{ }^{\circ} \mathrm{C}$. (a) High-P steel and $(b)$ low-P steel. SEM micrographs. 

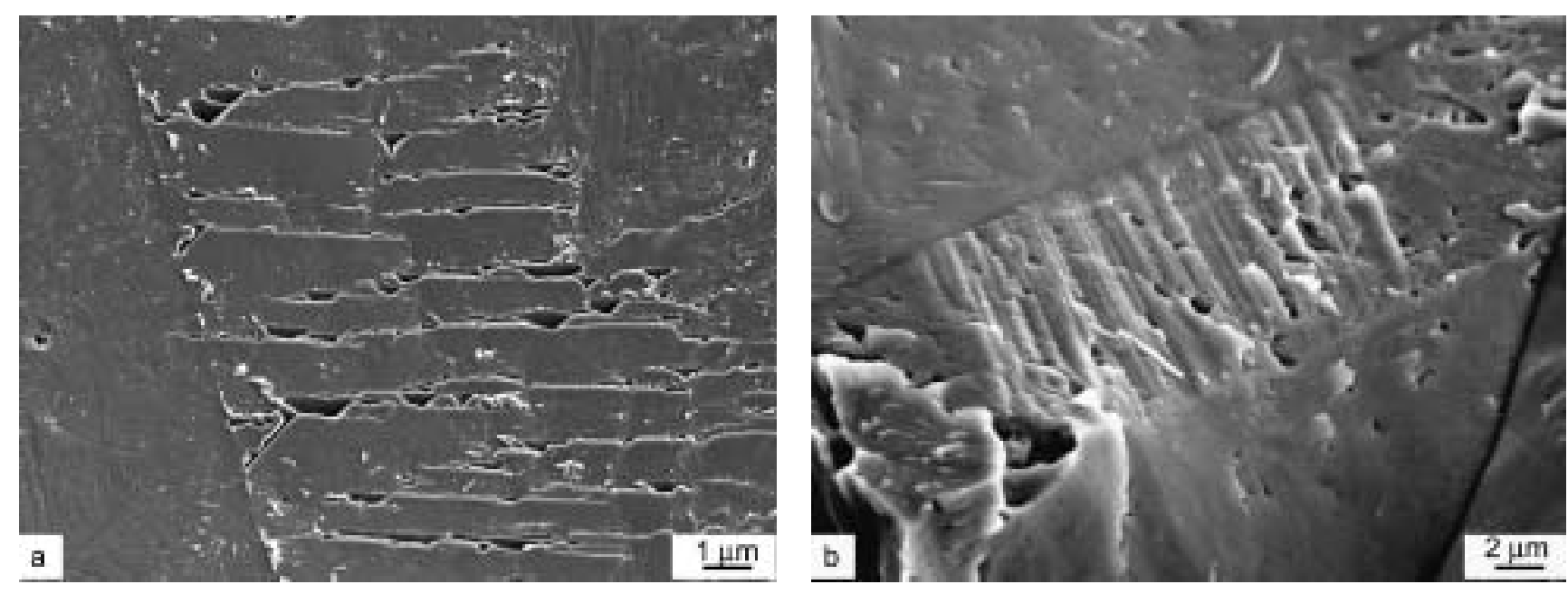

Fig. 12-Intergranular fracture surfaces of a high-P SAE 5160 steel austenitized at $1100{ }^{\circ} \mathrm{C}$, as-quenched, showing regions of parallel steps that correlate to the morphology of cementite/austenite interfaces found on early stages of cementite growth. (a) Parallel steps found on side of grain boundary and (b) parallel steps found in a twinned region of grain boundary. SEM micrographs.

\section{REFERENCES}

1. S.K. Banerji, C.J. McMahon, Jr., and H.C. Feng: Metall. Trans. A, 1978, vol. 9A, pp. 237-47.

2. N. Banyopadhyay and C.J. McMahon, Jr.: Metall. Trans. A, 1983 vol. 14A, pp. 1313-32.

3. G. Krauss and C.J. McMahon, Jr.: in Martensite, G.B. Olson and W.S. Owen, eds., ASM INTERNATIONAL, Materials Park, OH, 1992, pp. 295-321.

4. C.L. Briant: in Impurities in Engineering Materials, C.L. Briant, ed., Marcel Dekker, Inc., New York, NY, 1999, pp. 193-224.

5. G. Krauss: Iron Steel Inst. Jpn. Int., 1995, vol. 35, pp. 349-59.

6. G. Krauss: Metall. Mater. Trans. A, 2001, vol. 32A, pp. 861-77.

7. R.S. Hyde, G. Krauss, and D.K. Matlock: 40th MWSP Conf. Proc., ISS, Warrendale, PA, 1998, pp. 921-28.

8. H.J. Grabke: in Impurities in Engineering Materials, C.L. Briant, ed., Marcel Dekker, Inc., New York, NY, 1999, pp. 143-92.

9. J.P. Materkowski and G. Krauss: Metall. Trans. A, 1979, vol. 10A, pp. 1643-51.

10. G. Krauss: Metall. Trans. A, 1978, vol. 9A, pp. 1527-35.

11. R.S. Hyde, D.K. Matlock, and G. Krauss: Metall. Mater. Trans. A, 1994, vol. 25A, pp. 1229-40

12. V. Raghavan: Phase Diagrams of Ternary Iron Alloys; Part 3 Ternary Systems Containing Iron and Phosphorus, 1st ed., Indian Institute of Metals, Calcutta, 1988, pp. 33-44.

13. T. Ando and G. Krauss: Metall. Trans. A, 1981, vol. 12A, pp. 1283-90.

14. F.A. Darnwish, L.C. Pereira, C. Gatts, and M.L. Graca: Mater. Sci. Eng., 1991, vol. A132, pp. L5-L9.
15. A. Reguly: Ph.D. Thesis, Universidade Federal do Rio Grande do Sol, Porto Alegre, Brazil, 1999.

16. T. Maki, K. Tsuzaki, and I. Tamura: Trans. Iron Steel Inst. Jpn., 1986, vol. 20, pp. 207-14.

17. J.D. Wong, D.K. Matlock, and G. Krauss: 43rd MWSP Conf. Proc., ISS, Warrendale, PA, 2001, pp. 21-36.

18. G. Thomas: Metall. Trans. A, 1978, vol. 9A, pp. 439-50.

19. B.A. James, D.K. Matlock, and G. Krauss: 38th MWSP Conf. Proc., ISS, Warrendale, PA, 1997, vol. XXXIV, pp. 579-90.

20. E.L. Brown and G. Krauss: Metall. Trans. A, 1986, vol. 17A, pp. 31-36

21. R.A. Grange: Trans. ASM, 1966, vol. 59, pp. 26-48.

22. D.L. Yaney: Master's Thesis, Colorado School of Mines, Golden, CO, 1987.

23. H.I. Aaronson: in Decomposition of Austenite by Diffusional Processes, V.F. Zackay and H.I. Aaronson, eds., Interscience Publishers, New York, NY, 1962, pp. 387-542.

24. T. Ando and G. Krauss: Acta Metall., 1981, vol. 29, pp. 351-63.

25. N. Bandyopadhyay, J. Kameda, and C.J. McMahon, Jr.: Metall. Trans. A, 1983, vol. 14A, pp. 881-88.

26. Y. Weng and C.J. McMahon, Jr.: Mat. Sci. and Tech., 1987, vol. 3, pp. 207-216.

27. R.L. Bodner, J.R. Michael, S.S. Hansen, and R.I. Jaffee: 30th MWSP Conf. Proc., ISS, Warrendale, PA, 1988, pp. 173-94.

28. R.L. Bodner, T. Ohhashi, and R.I. Jaffee: Metall. Trans. A, 1989 vol. 20A, pp. 1445-60.

29. T. Majka: Master's Thesis, Colorado School of Mines, Golden, CO, 2001. 